\title{
Mechanisms of Impaired Exercise Capacity in Short Duration Experimental Hyperthyroidism
}

\author{
Wade H. Martin III, Robert J. Spina, Ellen Korte, Kevin E. Yarasheski, \\ Theodore J. Angelopoulos, Patti M. Nemeth, and Jeffrey E. Saffitz \\ Departments of Medicine, Pathology, and Neurology, Washington University School of Medicine, St. Louis, Missouri 63110
}

\begin{abstract}
To investigate the mechanism of reduced exercise tolerance in hyperthyroidism, we characterized cardiovascular function and determinants of skeletal muscle metabolism in 18 healthy subjects aged $26 \pm 1$ yr (mean \pm SE) before and after 2 wk of daily ingestion of $100 \mu \mathrm{g}$ of triiodothyronine $\left(\mathrm{T}_{3}\right)$. Resting oxygen uptake, heart rate, and cardiac output increased and heart rate and cardiac output at the same submaximal exercise intensity were higher in the hyperthyroid state $(P<0.05)$. However, maximal oxygen uptake decreased after $T_{3}$ administration (3.08 \pm 0.17 vs. $2.94 \pm 0.19 \mathrm{l} / \mathrm{min} ; P<0.001)$ despite increased heart rate and cardiac output at maximal exercise $(P<0.05)$. Plasma lactic acid concentration at an equivalent submaximal exercise intensity was elevated $25 \%(P<0.01)$ and the arteriovenous oxygen difference at maximal effort was reduced $(P$ $<0.05)$ in the hyperthyroid state. These effects were associated with a $21-37 \%$ decline in activities of oxidative ( $P$ $<0.001)$ and glycolytic $(P<0.05)$ enzymes in skeletal muscle and a $15 \%$ decrease in type IIA muscle fiber cross-sectional area $(P<0.05)$. Lean body mass was reduced $(P<0.001)$ and the rates of whole body leucine oxidation and protein breakdown were enhanced $(P<0.05)$. Thus, exercise tolerance is impaired in short duration hyperthyroidism because of decreased skeletal muscle mass and oxidative capacity related to accelerated protein catabolism but cardiac pump function is not reduced. (J. Clin. Invest. 1991. 88:2047-2053.) Key words: cardiac output • oxidative capacity • protein kinetics • skeletal muscle $\bullet$ thyrotoxicosis
\end{abstract}

\section{Introduction}

Hyperthyroidism is associated with impaired exercise tolerance that is widely believed to be due to decreased left ventricular function (1-3). However, studies in both man and experimental animals have shown that tachycardia and eccentric cardiac hypertrophy more than compensate for this effect, resulting in elevated cardiac output at rest and during exercise (4-6). Thus, it is not clear that the lower exercise capacity associated with thyrotoxicosis is caused by reduced cardiac function. Alternatively, such symptoms may be related to a skeletal myopathy

Address reprint requests to Wade Martin, M.D., Washington University School of Medicine, Dept. of Medicine, 4566 Scott Ave., Campus Box 8113, St. Louis, MO 63110.

Received for publication 25 March 1991 and in revised form 20 July 1991

J. Clin. Invest.

(C) The American Society for Clinical Investigation, Inc.

0021-9738/91/12/2047/07 \$2.00

Volume 88, December 1991, 2047-2053 that alters oxidative metabolism even during submaximal work. In this context, we hypothesized that induced hyperthyroidism would decrease exercise capacity in healthy human subjects because of a deleterious effect on skeletal muscle metabolism and that cardiac output would not be reduced during submaximal and maximal exercise. To test this hypothesis, we characterized oxygen uptake, cardiac output, plasma lactic acid, and other metabolic and physiologic responses to submaximal and maximal exercise in human subjects before and after induction of moderate hyperthyroidism. To elucidate the mechanism of altered skeletal muscle metabolism, we quantified muscle oxidative and glycolytic enzyme activities, muscle fiber type composition and cross-sectional area, and estimated whole body protein turnover and body composition in the same individuals in the euthyroid and hyperthyroid states.

\section{Methods}

Subjects. 18 subjects ( 11 men, 7 women) aged $26 \pm 1$ yr (mean \pm SE) were studied. All were judged to be healthy on the basis of a normal medical history, physical examination, resting electrocardiogram, and maximal treadmill exercise test. No subjects took regular medications, drank caffeine-containing beverages, or used tobacco on the days of experimental protocols. Two subjects played on a soccer team once a week but the remaining individuals were sedentary and none engaged in strenuous exercise more often than once a week. Subjects were instructed to maintain a similar level of activity throughout the investigation. They were studied during three or four separate laboratory visits in the euthyroid state and the same number of visits after they had taken $100 \mu \mathrm{g}$ of triiodothyronine $\left(\mathrm{T}_{3}\right)^{1}$ daily for $2 \mathrm{wk}$. The initial laboratory visit consisted of the medical evaluation, exercise stress test, and measurement of maximal oxygen uptake $\left(\mathrm{V}_{2} \max \right)$ in all subjects during treadmill exercise. On subsequent visits in both the euthyroid and hyperthyroid states, tissue was obtained from the gastrocnemius muscle of 14 subjects by percutaneous biopsy. Both before and after $T_{3}$ administration, nine individuals underwent measurements of cardiac output at rest and during submaximal and maximal exercise. Six were tested on the treadmill, and the remaining three were studied during cycle ergometer exercise to permit echocardiographic assessments of left ventricular size and function. Eight subjects completed a protocol to characterize the effect of hyperthyroidism on physiologic and metabolic responses to submaximal exercise. Heart rate and blood pressure data and blood samples for analysis of plasma catecholamines, lactic acid, free fatty acids, glycerol, glucose, and potassium were obtained after $30 \mathrm{~min}$ of supine rest, $10 \mathrm{~min}$ of quiet standing, $15 \mathrm{~min}$ of treadmill exercise at $75 \% \mathrm{~V}_{2} \max$, and $5 \mathrm{~min}$ postexercise. Changes in body composition and whole body protein metabolism were assessed from measurements of skinfold adiposity and estimates of fat-free mass made in nine subjects and analyses of $\left[1-^{13} \mathrm{C}\right]$ leucine turnover made in seven individuals before and after $T_{3}$ administration. The investigation

1. Abbreviations used in this paper: $\mathrm{LV}$, left ventricle; $\mathrm{T}_{3}$, triiodothyronine; $\dot{\mathrm{VO}}_{2} \max$, maximal oxygen uptake. 
was approved by the Human Studies Committee of Washington University. All subjects gave voluntary written informed consent for participation in the study.

Exercise capacity. Maximal oxygen uptake $\left(\dot{\mathrm{V}}_{2} \max \right)$ was quantified during multistage treadmill exercise to an endpoint of exhaustion. The treadmill protocol was designed from previous stress test data. Oxygen uptake and carbon dioxide production were measured every $30 \mathrm{~s}$ during exercise with an automated online system as described previously (7). Criteria for achievement of maximal exercise consisted of exhaustion of the subjects plus two out of three of the following end points: leveling off of oxygen uptake despite increasing treadmill work rate, attainment of age-predicted maximal heart rate, and a respiratory exchange ratio $>1.1$. Heart rate at rest and during exercise was calculated from three consecutive sinus beats of the electrocardiogram (ECG). Blood pressure was measured at rest and during exercise using a wall-mounted sphygmomanometer.

Cardiac output. Cardiac output was determined at rest and during submaximal and maximal exercise using the acetylene rebreathing technique as described previously $(8,9)$. Two measurements were made after $15 \mathrm{~min}$ of seated rest and one during the terminal $15 \mathrm{~s}$ of each of two 4-min bouts of submaximal exercise at 50 and $75 \% \dot{\mathrm{VO}}_{2} \max$. A final measurement was made in the last $15 \mathrm{~s}$ of a single 3-4-min bout of exercise at maximal effort. Subjects rested $10 \mathrm{~min}$ between exercise trials. Oxygen uptake and blood pressure were determined in the minute immediately preceding measurement of cardiac output. Heart rate and cardiac output were determined simultaneously. Stroke volume, arteriovenous oxygen difference, mean blood pressure, and total peripheral resistance were calculated from these data using standard formulae (9). Two-dimensionally guided M-mode echocardiograms of the left ventricle were obtained in three subjects immediately before measurement of cardiac output during seated rest and cycle ergometer exercise. Data were acquired in the parasternal short-axis view using a model 77020A Ultrasound Imaging System equipped with a $2.5 \mathrm{MHz}$ model 21200B transducer (Hewlett-Packard Co., Andover, MA). Left ventricular end diastolic and end systolic dimensions (LVEDD and LVESD, respectively) were determined according to recommendations of the American Society of Echocardiography $(10,11)$. Left ventricular function was quantified as fractional shortening (FS\%) using the relation FS $\%=[($ LVEDD - LVESD $) /$ LVEDD $] \times 100 \%$.

Submaximal exercise protocol. This protocol was conducted in the morning after an overnight fast. After arrival of subjects, electrodes were applied for ECG monitoring, a catheter was inserted into a forearm vein, and a blood pressure cuff was placed on the opposite arm. Subjects then rested in a quiet, darkened room in the supine posture for $30 \mathrm{~min}$. Blood pressure and heart rate were measured and a $10-\mathrm{ml}$ blood sample was drawn for assay of plasma norepinephrine, epinephrine, lactate, glucose, free fatty acids, glycerol, and potassium concentrations. Subjects then assumed the upright posture and stood quietly for $10 \mathrm{~min}$ after which heart rate and blood pressure were determined and blood was drawn for measurement of plasma catecholamines. Immediately thereafter, they exercised on the treadmill for $15 \mathrm{~min}$ at a work intensity requiring $75 \% \mathrm{~V}_{2}$ max. Oxygen uptake was verified by respiratory gas analysis throughout the protocol. Simultaneous physiologic data and a 10-ml blood sample were obtained in the final $60 \mathrm{~s}$. Exercise was then discontinued and the same parameters were measured after $5 \mathrm{~min}$ of seated rest. Blood samples were immediately aliquoted to previously prepared tubes and placed on ice. Plasma was separated in a refrigerated centrifuge and stored at $-70^{\circ} \mathrm{C}$ until assayed. Samples obtained from the same individuals in the euthyroid and hyperthyroid states were analyzed simultaneously. Plasma $T_{3}, T_{4}$, and thyroid-stimulating hormone levels were determined by enzymatic immunoassay (IMX TSH Assay Kit; Abbott Diagnostics, Abbott Park, IL) on blood samples drawn the morning after (12-24 h) the most recent dose of $T_{3}$. Norepinephrine and epinephrine were assayed by a single isotope derivative (radioenzymatic) method (12). Lactate and glycerol were analyzed enzymatically $(13,14)$. Glucose was measured using the glucose oxidase method on a glucose analyzer (Beckman In- struments, Inc., Fullerton, CA). Nonesterified plasma free fatty acids were quantified using an enzymatic colorimetric method (Waco Pure Chemical Industries, Ltd., Osaka, Japan). Potassium was determined with an ion-selective electrode via an Ektachem analyzer (Eastman Kodak Co., Rochester, NY).

Skeletal muscle biopsy procedure. Skeletal muscle tissue samples $(50-100 \mathrm{mg})$ were obtained by percutaneous biopsy of the gastrocnemius muscle using the Bergstrom needle technique (7) modified by application of suction to the needle shaft to increase tissue yield (15). Blood and connective tissue were removed from excised muscle samples under a dissecting microscope and the tissue was divided into two portions. One portion was frozen quickly in isopentane cooled to its freezing point in liquid nitrogen and stored at $-70^{\circ}$ for subsequent biochemical analyses. The other portion was mounted in embedding medium (OCT), frozen as described above, and stored for later histochemical analysis of muscle fiber type and cross-sectional area.

Histochemical analysis. Frozen OCT-mounted samples of muscle from the same subject in the euthyroid and hyperthyroid states were placed side-by-side in a cryomicrotome and cut simultaneously into cross-sections $12 \mu \mathrm{m}$ in thickness. Both sections were applied to the same coverslip for delineation of skeletal muscle fiber type composition by histochemical staining for myofibrillar ATPase activity after preincubation in buffer at $\mathrm{pH} 4.55$ as described by Dubowitz et al. (16). Individual skeletal myocytes in both biopsies were classified as slowtwitch oxidative (type I), fast-twitch oxidative glycolytic (type IIA), or fast-twitch glycolytic (type IIB) fibers by dark, light, or intermediate staining intensities, respectively (17). The percentage of fibers in each category was determined from at least 200 contiguous fibers per section. Cross-sectional areas of representative fibers of each type were measured in selected sections with a computer-assisted planimeter (18).

Muscle oxidative and glycolytic enzyme activities. Activities of citrate synthase (CS), malate dehydrogenase (MDH), $\beta$-hydroxyacyl CoA dehydrogenase ( $\beta O A C)$, phosphofructokinase (PFK), and lactate dehydrogenase (LDH) were determined in homogenates of gastrocnemius biopsies. Samples were homogenized at high speed with a motor driven tissue grinder (Con-Torque; Eberbach Corp., Ann Arbor, MI). The homogenization medium contained $5 \mathrm{mM} \beta$-mercaptoethanol, $0.5 \mathrm{mM}$ ethylenediaminetetraacetic acid, $0.02 \% \mathrm{BSA}$, and $50 \%$ glycerol in $20 \mathrm{mM}$ sodium phosphate buffer, $\mathrm{pH}$ 7.4. Preliminary studies conducted previously with rabbit and monkey skeletal muscle revealed negligible loss of activity of all enzymes assayed during prolonged (several months) storage of fresh frozen tissue at $-70^{\circ} \mathrm{C}(19)$. Samples from the euthyroid and hyperthyroid states were assayed concurrently. Enzyme activities were quantified fluorometrically at $25^{\circ} \mathrm{C}$ and expressed in moles per kilogram protein per hour as described in detail previously (19). Protein was determined with a bicinchoninic acid protein assay kit (Sigma Chemical Co., St. Louis, MO).

Whole body protein turnover rate. The rates of whole body leucine turnover, oxidation, nonoxidative disposal (i.e. protein synthesis rate), and protein breakdown were measured during a 3-h constant infusion of $\left[1-{ }^{13} \mathrm{C}\right]$-leucine $(0.6 \mathrm{mg} / \mathrm{kg}$ per $\mathrm{h})$ after an overnight fast $(20,21)$. At 30 -min intervals, blood samples were collected and analyzed for plasma ${ }^{13} \mathrm{C}$ - $\alpha$-ketoisocaproate enrichment (22) and expired air samples were collected for ${ }^{13} \mathrm{CO}_{2}$ enrichment analysis (23). Food intake on the day before infusions performed in the euthyroid state was documented by a research dietitian and duplicated by subjects on the day before infusions after $\mathrm{T}_{3}$ treatment.

Body composition. Percent body fat and fat-free mass were estimated from measurements of skinfold adiposity and body weight. Skinfold thickness was assessed at six sites with a Lange caliper (Cambridge Scientific, Inc., Cambridge, MD) as described by Behnke and Wilmore (24). Percent body fat was estimated from the sum of these measurements (25). Fat-free mass (FFM) was calculated as FFM $=$ total body weight $/ 100 \times(100-\%$ fat $)$.

Statistics. The effect of hyperthyroidism on exercise capacity and other physiologic measurements was evaluated by analysis of variance 
or Student's $t$ tests for paired observations. Statistical differences were considered significant at $P<0.05$. Data are expressed as means \pm SE.

\section{Results}

Biochemical and physiologic manifestations of hyperthyroidism. Daily administration of $100 \mu \mathrm{g}$ of $\mathrm{T}_{3}$ for 2 wk produced laboratory and physiologic evidence of moderate hyperthyroidism. Plasma $T_{3}$ levels increased $350 \%$ ( $121 \pm 6$ to $\left.543 \pm 66 \mathrm{ng} / \mathrm{dl}\right)$ and thyroid stimulating hormone decreased from $1.5 \pm 0.2 \mu \mathrm{U} /$ $\mathrm{ml}$ initially to undetectable levels in 13 subjects and to $0.3 \pm 0.1$ $\mu \mathrm{U} / \mathrm{ml}$ in the remaining five individuals $(P<0.001)$. A fall in plasma thyroxine concentration occurred in all seven subjects in whom it was measured $(7.6 \pm 0.7$ to $2.7 \pm 0.4 \mu \mathrm{g} / \mathrm{dl} ; P$ $<0.001)$. Supine resting heart rate increased $(59 \pm 2$ vs. $72 \pm 3$ beats/min; $P<0.005$ ) and subjects tended to lose weight $(76.1 \pm 4.0$ to $75.1 \pm 4.0 \mathrm{~kg} ; P<0.06)$. Nine participants had no somatic complaints during the course of the protocol and 15 were unaware of any alteration in food consumption. Two men experienced slight insomnia for several days after beginning $T_{3}$ ingestion and one male subject reported increased appetite and food consumption but only gained $0.3 \mathrm{~kg}$ of weight. Six individuals (two men, four women) complained of headaches which resolved in four instances within 3-4 d of continued $T_{3}$ administration. The two remaining subjects (both women) were the only participants to experience nausea and anorexia but their symptoms were mild and accompanied by weight loss that was similar to that of the other subjects $(1-1.5 \mathrm{~kg})$. There were no adverse cardiovascular effects of the study.

Exercise capacity. Maximal oxygen uptake during treadmill exercise decreased by $5 \%$ in the hyperthyroid state $(3.08 \pm 0.17$ to $2.94 \pm 0.19 \mathrm{l} / \mathrm{min} ; P<0.001)$. This effect occurred despite a higher heart rate ( $195 \pm 2$ vs. $203 \pm 3$ beats/min; $P<0.001)$ and respiratory exchange ratio $(1.12 \pm 0.02$ vs. $1.18 \pm 0.02 ; P=0.05$ ) during maximal exercise after $\mathrm{T}_{3}$ administration. Treadmill time for the same exercise protocol was $10 \%$ shorter when subjects were hyperthyroid $(7.39 \pm 0.31$ vs. $6.68 \pm 0.37 \mathrm{~min} ; P=0.01)$. Minute ventilation at maximal effort did not change (100.0 \pm 5.3 vs. $97.9 \pm 5.3$ liters/min; NS).

Cardiac output. Cardiac output during seated rest increased by $23 \%$ in the hyperthyroid state $(5.2 \pm 0.7$ vs. $6.4 \pm 0.7 ; P$ $<0.001)$ because of a faster heart rate $(73 \pm 5$ vs. $86 \pm 6$ beats/ min; $P<0.001)$; stroke volume did not change $(76 \pm 13$ vs. $80 \pm 11 \mathrm{ml}$; NS). Oxygen uptake was also higher $(0.35 \pm 0.01 \mathrm{vs}$. $0.38 \pm 0.01 \mathrm{l} / \mathrm{min} ; P<0.05$ ) but the arteriovenous oxygen difference and blood pressure during seated rest were not signifcantly different in the euthyroid and hyperthyroid states. Resting total peripheral resistance was $24 \%$ lower during $T_{3}$ administration $\left(1,472 \pm 180\right.$ vs. $\left.1,124 \pm 103 \mathrm{dyn} \cdot \mathrm{s} \cdot \mathrm{cm}^{-5} ; P<0.001\right)$.

Hyperthyroidism augmented cardiac output during both submaximal and maximal exercise $(P<0.01)$. The increase ranged from 6 to $9 \%$ and was significant at both 75 and $100 \%$ of maximal effort (Fig. $1 \mathrm{~A}$ ). The elevated cardiac output was entirely due to a faster heart rate (Fig. $1 B$ ); stroke volume was not different in the euthyroid and hyperthyroid states at any level of exercise. The arteriovenous oxygen difference during submaximal exercise was not altered by hyperthyroidism but was lower at maximal effort during $T_{3}$ administration (Fig. 1 $C)$. This effect was not explained by a change in hematocrit which remained constant $(40.8 \pm 1.3$ vs. $41.0 \pm 2.5 \%$; NS). Exercise blood pressure during measurement of cardiac output was

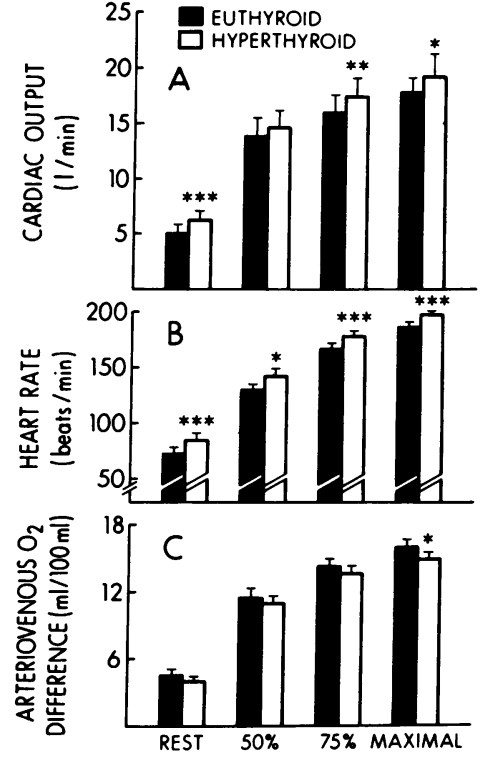

Figure 1. Effect of hyperthyroidism on cardiac output $(A)$, heart rate $(B)$, and arteriovenous oxygen difference $(C)$ during seated rest and treadmill exercise at $50 \%, 75 \%$, and maximal effort. Date are means $\pm \mathrm{SE}$ for four men and five women. ${ }^{*} P<0.05 ;{ }^{* *} P$ $<0.01 ;{ }^{* * *} P<0.001$ vs euthyroid.

similar for the euthyroid and hyperthyroid studies; however, total peripheral resistance tended to be lower during submaximal exercise and was significantly reduced at maximal effort in the hyperthyroid state $\left(504 \pm 36\right.$ vs. $456 \pm 34 \mathrm{dyn} \cdot \mathrm{s} \cdot \mathrm{cm}^{-5} ; P$ $<0.001$ ).

Left ventricular (LV) size and function during seated rest were not significantly influenced by $T_{3}$ administration in the three subjects undergoing echocardiography. Thus, measurements of $\mathrm{LV}$ dimensions at end diastole $(3.7 \pm 0.5$ vs. $3.6 \pm 0.6$ $\mathrm{cm}$ before vs. after $\left.\mathrm{T}_{3} ; \mathrm{NS}\right)$ and end systole $(2.4 \pm 0.6$ vs. $2.2 \pm 0.5$ $\mathrm{cm}$; NS) and LV fractional shortening $(37.6 \pm 5.8 \%$ vs. $39.2 \pm 4.0 \%$; NS) revealed no evidence of altered preload or resting LV dysfunction in these individuals. During exercise, the LV end systolic dimension decreased $(P=0.02)$ and fractional shortening increased $(P=0.01)$, consistent with an enhanced LV contractile state. However, there were no differences in LV dimensions or fractional shortening (FS) before and after $\mathrm{T}_{3}$ administration $(43.0 \pm 6.6 \%$ vs. $46.0 \pm 2.1 \%$ for FS at $75 \%$ peak effort and $42.5 \pm 2.0 \%$ vs. $46.1 \pm 4.3 \%$ at peak effort; NS). These findings are consistent with the absence of an effect of short duration hyperthyroidism on stroke volume during exercise and suggest that decreased exercise capacity in the hyperthyroid state was not mediated by reduced $\mathrm{LV}$ function.

Submaximal exercise protocol. Despite evoking an elevated cardiac output response to brief submaximal and maximal treadmill exercise, hyperthyroidism resulted in a $25 \%$ greater plasma lactic acid response to more prolonged submaximal treadmill work of the same intensity (oxygen uptake $2.13 \pm 0.16$ vs. $2.15 \pm 0.19 \mathrm{l} / \mathrm{min}$; NS) (Table I). There was no evidence that this effect was related to a shortage of other plasma metabolic substrates such as free fatty acids or glucose, both of which were similar during exercise before and after $\mathrm{T}_{3}$ administration ( $\mathrm{Ta}$ ble I). Plasma potassium and the respiratory exchange ratio were also unaltered. However, minute ventilation was greater $(59.8 \pm 4.1$ vs. $67.9 \pm 6.2 \mathrm{l} / \mathrm{min} ; P<0.005)$ and systolic blood pressure higher (Fig. $2 \mathrm{~A}$ ) in the hyperthyroid state, consistent with augmented stimulation of skeletal muscle chemoreceptors by increased muscle lactic acid concentration and lower $\mathrm{pH}$ (26) in the hyperthyroid state. Nevertheless, plasma catechol- 
Table I. Effect of Hyperthyroidism on Plasma Lactate and Other Metabolic Parameters at Rest and after 15 min of Submaximal Exercise of the Same Intensity

\begin{tabular}{llc}
\hline & \multicolumn{2}{c}{ Thyroid status } \\
\cline { 2 - 3 } \multicolumn{1}{c}{ Plasma substrate } & Euthyroid & Hyperthyroid \\
\hline Lactate $(m M)$ & & \\
$\quad$ Rest & $1.0 \pm 0.1$ & $1.1 \pm 0.1$ \\
$\quad$ Exercise & $5.2 \pm 0.6^{\ddagger}$ & $6.5 \pm 0.7^{\ddagger 1}$ \\
Glucose $(m g / d l)$ & & \\
$\quad$ Rest & $84 \pm 2$ & $89 \pm 2^{8}$ \\
Exercise & $81 \pm 2$ & $80 \pm 4$ \\
Free fatty acids $(m M)$ & & \\
Rest & $0.4 \pm 0.1$ & $0.4 \pm 0.03$ \\
$\quad$ Exercise & $0.3 \pm 0.1$ & $0.4 \pm 0.1$ \\
Glycerol $(m M)$ & & \\
$\quad$ Rest & $0.05 \pm 0.01$ & $0.07 \pm 0.01$ \\
Exercise & $0.14 \pm 0.02^{\ddagger}$ & $0.17 \pm 0.01^{\ddagger}$ \\
Potassium $(m M)$ & & \\
Rest & $4.1 \pm 0.1$ & $4.3 \pm 0.1$ \\
Exercise & $4.7 \pm 0.2^{*}$ & $4.8 \pm 0.1^{*}$ \\
Respiratory exchange ratio & & \\
Rest & $0.78 \pm 0.02$ & $0.79 \pm 0.03$ \\
Exercise & $0.96 \pm 0.01^{\ddagger}$ & $0.97 \pm 0.01^{\ddagger}$ \\
& &
\end{tabular}

Data are means \pm SE for six men and two women. ${ }^{*} P<0.05 ;{ }^{\ddagger} P$ $<0.01$ vs. rest. ${ }^{8} P<0.05$; ${ }^{\prime \prime} P<0.01$ vs. euthyroid.

amine levels were not different (Fig. $2 B$ ) suggesting that hyperthyroidism did not enhance the sympathoadrenal response to exercise eliciting more than fivefold increments in epinephrine and norepinephrine concentrations above the supine resting state $(P<0.001)$. Systolic pressure after 10 min of quiet standing was only slightly higher and diastolic pressure responses to standing and exercise were not influenced by hyperthyroidism.
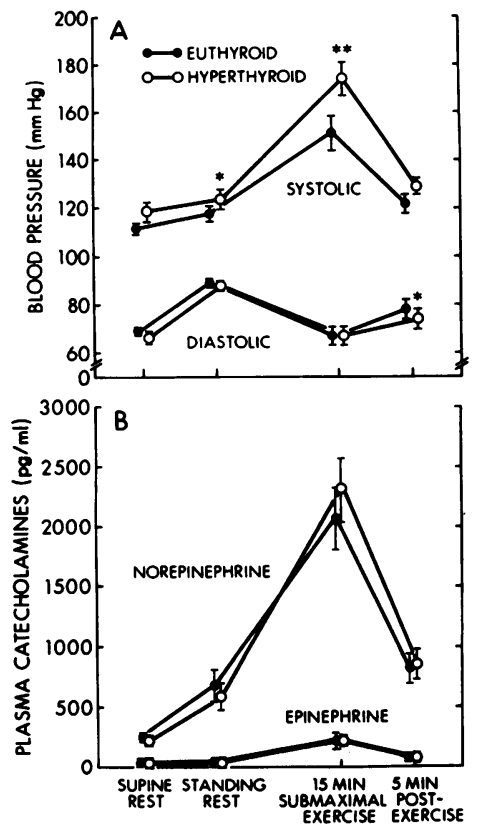

Figure 2. Effect of hyperthyroidism on systolic and diastolic blood pressures $(A)$ and plasma norepinephrine and epinephrine concentrations $(B)$ after 30 min of supine rest, $10 \mathrm{~min}$ of standing, 15 min of submaximal exercise of the same intensity, and $5 \mathrm{~min}$ postexercise. Data are means \pm SE for six men and two women. ${ }^{*} P<0.05 ;{ }^{* *} P$ $<0.01$ vs. euthyroid.
Epinephrine rose $\sim 20 \%$ and norepinephrine increased $170 \%$ with upright posture on both evaluations (all $P<0.001$ ).

Skeletal muscle fiber type and fiber cross-sectional area. Muscle fiber type composition was determined in $333 \pm 24$ contiguous fibers per biopsy in the euthyroid state and $346 \pm 23$ fibers after $\mathrm{T}_{3}$ administration. Hyperthyroidism did not significantly alter muscle fiber type composition (Table II). However, type IIA fibers became smaller (Table II) providing evidence for selective muscle fiber atrophy even after only 2 wk of $T_{3}$ administration.

Skeletal muscle enzyme activities. The most striking effect of 2 wk of hyperthyroidism on skeletal muscle was on the activities of oxidative enzymes (Fig. 3). A highly significant decrease in activities of these enzymes was observed, regardless of whether they were involved in fatty acid or carbohydrate metabolism. The decline ranged from $26 \%$ for $\beta$-hydroxyacyl CoA dehydrogenase, a component of the fatty acid oxidation pathway, to $37 \%$ for citrate synthase $(P<0.001)$, which catalyzes the first step in the tricarboxylic acid cycle. The activities of glycolytic enzymes also were reduced. Activity of phosphofructokinase, the major regulatory enzyme for glycolysis fell $26 \%$, and that of lactate dehydrogenase declined $21 \%$.

Body composition and protein metabolism. Administration of $\mathrm{T}_{3}$ did not elicit a change in percent body fat, estimated from measurements of skinfold thickness $(17.3 \pm 1.2$ vs. $17.8 \pm 1.3 \%$; NS). However, hyperthyroidism was accompanied by a significant decrease in fat-free mass $(66.2 \pm 5.3$ vs. $64.4 \pm 5.3 \mathrm{~kg} ; P$ $<0.001)$. Nevertheless, weight loss occurred during the first few days of $\mathrm{T}_{3}$ administration and body weight remained stable $(86.4 \pm 2.8$ vs. $86.5 \pm 2.8 \mathrm{~kg}$; NS) for the time interval during which protein turnover studies were performed in the hyperthyroid state. Protein turnover data demonstrated that the $T_{3}$-induced decrease in fat-free mass, skeletal muscle enzyme activities, and fiber cross-sectional area was associated with enhanced protein breakdown and leucine oxidation rates (Table III). These findings provide evidence that hyperthyroidism accelerates the rates of protein breakdown $(+12 \%)$ and amino acid oxidation $(+24 \%)$ in excess of a small increase in the rate of protein synthesis $(+9 \%)$, thereby resulting in net protein loss.

Table II. Effect of Hyperthyroidism on Muscle Fiber Type Composition and Fiber Cross-sectional Area of Gastrocnemius Biopsies

\begin{tabular}{lccc}
\hline & \multicolumn{2}{c}{ Thyroid status } & \\
\cline { 2 - 3 } \multicolumn{1}{c}{ Fiber type } & Euthyroid & Hyperthyroid & \% change \\
\hline I & & & \\
$\quad \begin{array}{lcc}\text { Percent of total } \\
\text { Fiber area }\left(\mu \mathrm{m}^{2}\right)\end{array}$ & $64.3 \pm 5.1$ & $61.4 \pm 4.8$ & -5 \\
IIA & $3513 \pm 334$ & $3416 \pm 273$ & -3 \\
$\quad$ Percent of total & $23.7 \pm 3.4$ & $23.9 \pm 2.6$ & +1 \\
$\quad$ Fiber area $\left(\mu \mathrm{m}^{2}\right)$ & $4768 \pm 544$ & $4035 \pm 390$ & $-15^{*}$ \\
IIB & & & \\
$\quad \begin{array}{l}\text { Percent of total } \\
\text { Fiber area }\left(\mu \mathrm{m}^{2}\right)\end{array}$ & $12.0 \pm 4.0$ & $14.7 \pm 3.6$ & +23 \\
& $3591 \pm 378$ & $3330 \pm 338$ & -7 \\
\hline
\end{tabular}

Data are means $\pm \mathrm{SE}$ for seven men and seven women. ${ }^{*} P<0.05$ vs. euthyroid. 


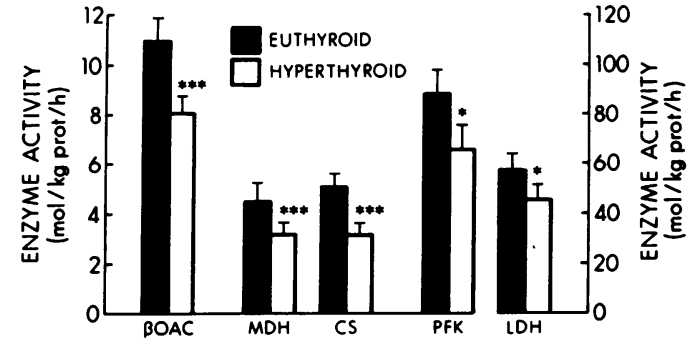

Figure 3. Effect of hyperthyroidism on activities of oxidative and glycolytic enzymes in homogenates of human gastrocnemius muscle. $\beta O A C$, $\beta$-hydroxyacyl CoA dehydrogenase; $M D H$, malate dehydrogenase; $C S$, citrate synthase; $P F K$, phosphofructokinase; $L D H$, lactate dehydrogenase. Data are means \pm SE for six men and seven women. ${ }^{*} P<0.05 ;{ }^{* * *} P<0.001$ vs. euthyroid.

\section{Discussion}

In this investigation 2 wk of $\mathrm{T}_{3}$-induced hyperthyroidism resulted in diminished exercise capacity despite increased heart rate and cardiac output during maximal and submaximal work. Manifestations of lower exercise capacity were evident during both maximal and submaximal effort and included decreased maximal oxygen uptake and a higher plasma lactic acid concentration at the same submaximal oxygen uptake. The reduced arteriovenous oxygen difference at maximal effort, decreased skeletal muscle oxidative capacity and fiber cross-sectional area, and enhanced rate of whole body protein breakdown in the presence of higher cardiac output are consistent with the interpretation that a peripheral mechanism was responsible for diminished exercise capacity in the hyperthyroid state.

Maximal oxygen uptake is the greatest attainable product of cardiac output and arteriovenous oxygen difference during relatively brief incremental exercise to exhaustion (27). Thus, exercise capacity is determined by both central and peripheral cardiovascular and metabolic factors. Maximal cardiac output is the highest product of heart rate and stroke volume, the latter being partly but not completely dependent on the left ventricular ejection fraction (28). Results of several recent investigations have attributed the impaired exercise capacity of human hyperthyroidism to a relatively modest decrease in left ventricular ejection fraction (1-3). However, it is difficult to reconcile these reports with evidence from both experimental animals

Table III. Effect of Hyperthyroidism on Whole Body Protein Turnover Rate

\begin{tabular}{lcc}
\hline \multirow{1}{*}{ Measurement } & \multicolumn{2}{c}{ Thyroid status } \\
\cline { 2 - 3 } & Euthyroid & Hyperthyroid \\
\hline $\begin{array}{l}\text { Leucine oxidation } \\
\text { Rate }(\mu \mathrm{mol} / \mathrm{kgFFM} / \mathrm{h})\end{array}$ & $29.2 \pm 2.2$ & $36.1 \pm 1.5^{*}$ \\
$\begin{array}{l}\text { Protein synthesis } \\
\text { Rate }(\mu \mathrm{mol} / \mathrm{kg} \mathrm{FFM} / \mathrm{h})\end{array}$ & $117 \pm 4$ & $128 \pm 5^{5}$ \\
$\begin{array}{l}\text { Protein breakdown } \\
\text { Rate }(\mu \mathrm{mol} / \mathrm{kg} \mathrm{FFM} / \mathrm{h})\end{array}$ & $146 \pm 4$ & $164 \pm 4^{\ddagger}$ \\
\hline
\end{tabular}

Data are means \pm SE for seven men. ${ }^{*} P<0.05 ;{ }^{\ddagger} P<0.01 ;{ }^{\S} P$ $=0.057$ vs. euthyroid. and man that hyperthyroidism also causes increased heart rate, stroke volume, and cardiac output and may cause cardiac enlargement, hypertrophy, or augmented contractility (4-6). Most exercise studies of left ventricular ejection fraction in spontaneously hyperthyroid human subjects did not include measurements of stroke volume and cardiac left ventricular output (29) and were conducted during supine exercise which elicits a lower peak heart rate and different hemodynamic responses than upright work (30). In contrast, our data were obtained during upright exercise and included measurements of cardiac output at an exercise heart rate and respiratory exchange ratio of 200 beats/min and 1.15 , respectively, coincident with exhaustion of the subjects. Although we did not assess left ventricular ejection fraction under these conditions, cardiac stroke volume was similar in the euthyroid and hyperthyroid states. Our data indicate that higher exercise cardiac output was related to a faster heart rate rather than increased stroke volume. These findings do not exclude reduced left ventricular ejection fraction but suggest that it does not explain the decreased exercise capacity in short duration human hyperthyroidism.

Several lines of evidence provide independent support for a peripheral mechanism of decreased exercise capacity in the hyperthyroid state. Plasma lactic acid concentration was increased during submaximal work at the same metabolic rate in conjunction with a reduction of the arteriovenous oxygen difference at maximal effort. In the context of higher cardiac output, unchanged hematocrit, and lower total peripheral resistance, these data suggest that oxidative metabolism was decreased and/or the rate of glycolysis was accelerated in exercising skeletal muscle. Quantification of oxidative enzyme activities in skeletal muscle biopsies yielded direct biochemical evidence of a decline in muscle oxidative capacity after $\mathrm{T}_{3}$ administration. Activities of enzymes required for oxidative metabolism of both carbohydrates and fatty acids were reduced. The 26-37\% decrement in muscle oxidative capacity was equivalent in magnitude to that observed in an earlier study of highly trained athletes after several weeks of markedly reduced physical activity (31). In the latter investigation, the correlation between decreased muscle oxidative capacity and increased plasma lactate during submaximal exercise was $>0.90$. Thus, the fall in muscle oxidative capacity likely played an important role in mediating the greater increase in plasma lactic acid concentration during exercise after $T_{3}$ administration.

Several major differences between effects of deconditioning and hyperthyroidism indicate that alterations induced by $T_{3}$ administration were probably not a result of decreased physical activity. Cardiac stroke volume decreases and plasma catecholamines during exercise increase with deconditioning $(11,30$, 31 ) but no change in either of these measurements was observed in the current investigation. A previous study in our laboratory demonstrated that skeletal muscle phosphofructokinase activity is not altered and lactate dehydrogenase activity increases (31) with deconditioning but activities of both enzymes declined after $T_{3}$ administration. Finally, the respiratory exchange ratio during submaximal exercise increases with deconditioning indicating a shift in favor of carbohydrate fuel sources that was not observed in the current study of hyperthyroidism. Thus, a variety of discrepancies between effects of $T_{3}$ administration and deconditioning suggest that our results cannot be explained by decreased physical activity. 
Because several days of excess thyroid hormone treatment are well known to increase resting metabolic rate, mitochondrial mass, and skeletal muscle oxidative capacity in some species of experimental animals (32-34), we were surprised by the highly significant decrease in oxidative capacity of human skeletal muscle after $\mathrm{T}_{3}$ administration. However, in experimental animals, the effect of thyroid hormones on mitochondrial mass and enzyme activities varies greatly among different species and tissues (33) and even among separate fiber types of skeletal muscle tissue (35). Only a slight or no increase in oxidative capacity occurred in fast-twitch glycolytic rat hindquarter muscles despite a two- to threefold rise in oxidative activity of neighboring slow-twitch muscles. Larger doses of thyroid hormones than were administered in the present study were given to elicit these effects (35). There was little or no rise in muscle oxidative capacity in guinea pigs and a decrease in rabbits after excess thyroid hormone administration (33). The very limited information available in man was obtained in small cross-sectional comparisons of hyperthyroid and euthyroid human subjects $(36,37)$. These studies reported conflicting results. However, the absence of a greater skeletal muscle oxidative capacity in thyrotoxic patients is consistent with findings of the present longitudinal investigation. Clinical symptoms of poor exercise tolerance in hyperthyroid human subjects are explainable on the basis of decreased rather than increased skeletal muscle oxidative capacity.

Measurements of body composition, whole body protein turnover, and muscle fiber cross-sectional area using independent techniques indicated that the decline in skeletal muscle oxidative capacity in the hyperthyroid state was likely to be related to accelerated protein catabolism. The tendency for subjects to lose weight after $\mathrm{T}_{3}$ administration was entirely explained by a decrease in fat-free mass, $\sim 40 \%$ of which is comprised of skeletal muscle. Rates of leucine oxidation and whole body protein breakdown were both enhanced indicating that protein catabolism occurred in the hyperthyroid state. Similar findings have been reported by other investigators (38). In the current study, the cross-sectional area of type IIA muscle fibers was smaller after $T_{3}$ administration providing additional evidence that skeletal muscle is a site of augmented protein catabolism in the hyperthyroid state.

The $T_{3}$ administration protocol used in this investigation resulted in mild to moderate hyperthyroidism of relatively brief duration. It can be argued that the decrease in exercise capacity was modest and therefore the effects of this protocol are not characteristic of those occurring with spontaneous hyperthyroidism. However, plasma $\mathrm{T}_{3}$ and TSH levels in the hyperthyroid state were very similar to those reported in studies of spontaneous hyperthyroidism $(1-4,36,37)$. Characteristic manifestations of $T_{3}$ excess included elevations of heart rate, cardiac output, resting oxygen uptake, and decreased total peripheral resistance. Subjects in this investigation were young and healthy, whereas in previous studies of spontaneous hyperthyroidism they were often older and may have had occult cardiovascular disease or other common chronic illnesses which could have introduced confounding effects. Although we do not discount the fact that a longer duration of hyperthyroidism may result in more severe impairments of exercise capacity, cardiac function, or skeletal muscle metabolism, our findings are consistent with known clinical sequelae of hyperthyroidism as well as with the increased resting and exercise cardiac output reported in thyrotoxic experimental animals and man (4-6) and elevated plasma lactic acid concentrations during submaximal exercise in patients with spontaneous hyperthyroidism (37). Our data confirm these observations in healthy subjects under more stringent experimental conditions and provide a more complete biochemical and physiologic basis for exercise intolerance in human hyperthyroidism.

In summary, we have demonstrated that maximal and submaximal exercise capacity are decreased in human subjects after 2 wk of excess $T_{3}$ administration that resulted in elevated resting and exercise cardiac output. Lower maximal oxygen uptake, reduced arteriovenous oxygen difference at maximal effort, and higher plasma lactic acid concentration during submaximal exercise were explained by a $26-37 \%$ decrease in skeletal muscle oxidative capacity. Hyperthyroidism also elicited a decrease in lean body mass, increases in whole body leucine oxidation and protein breakdown rates, and a reduction in type IIA skeletal muscle fiber cross-sectional area. These data suggest that impaired exercise capacity of hyperthyroidism is not caused by left ventricular dysfunction but is related to decreased skeletal muscle oxidative capacity that may be a consequence of skeletal muscle atrophy and accelerated protein catabolism.

\section{Acknowledgments}

The authors acknowledge Ms. Alka Bansal, Ms. Rati Choksi, Ms. May Chen, and Mr. Robert Hickner for technical assistance, Dr. John O. Holloszy and Dr. Philip E. Cryer for constructive suggestions, and Ms. Phyllis Anderson for preparation of the typescript.

This work was supported by National Heart, Lung, and Blood Institute grants HL-41290 and HL-17646, Specialized Center of Research on Ischemic Heart Disease, and by grant RR00036 to the General Clinical Research Center. R.J. Spina was supported by Institutional National Research Service Award AG-00078, K. E. Yarasheski by Research Career Development Award AG00444, and T. J. Angelopoulos by National Institute on Aging grant AG05562. J. E. Saffitz is an Established Investigator of the American Heart Association.

\section{References}

1. Shafer, R. B., and J. A. Bianco. 1980. Assessment of cardiac reserve in patients with hyperthyroidism. Chest. 78:269-273.

2. Forfar, J. C., A. L. Muir, S. A. Sawers, and A. D. Toft. 1982. Abnormal left ventricular function in hyperthyroidism: evidence for a possible reversible cardiomyopathy. N. Engl. J. Med. 307:1165-1170.

3. Cavallo, A., A. Casta, H. D. Fawcett, M. L. Nusynowitz, and W. J. Wolf. 1985. Is there a thyrotoxic cardiomyopathy in children? J. Pediatr. 107:531-536.

4. Massey, D. G., M. R. Becklake, J. M. McKenzie, and D. V. Bates. 1967. Circulatory and ventilatory response to exercise in thyrotoxicosis. $N$. Engl. $J$. Med. 276:1104-1112

5. Goldman, S., M. Olajos, H. Friedman, W. R. Roeske, and E. Morkin. 1982. Left ventricular performance in conscious thyrotoxic calves. Am. J. Physiol. 242(Heart Circ. Physiol. 11):H113-H121.

6. Hammond, H. K., F. C. White, I. L. O. Buxton, P. Saltzstein, L. L. Brunton, and J. C. Longhurst. 1987. Increased myocardial $\beta$-receptors and adrenergic responses in hyperthyroid pigs. Am. J. Physiol. 252(Heart Circ. Physiol. 21):H283-H290.

7. Martin, W. H., A. R. Coggan, R. J. Spina, and J. E. Saffitz. 1989. Effects of fiber type and training on $\beta$-adrenoceptor density in human skeletal muscle. Am. J. Physiol. 257(Endocrinol. Metab. 20):E736-E742.

8. Triebwasser, J. H., R. L. Johnson, B. P. Burpo, J. C. Campbell, W. C. Reardon, and C. G. Blomqvist. 1977. Noninvasive determination of cardiac output by a modified acetylene rebreathing procedure utilizing mass spectrometer measurements. Aviat. Space Environ. Med. 48:203-209.

9. Martin, W. H., J. Montgomery, P. G. Snell, J. R. Corbett, J. J. Sokolov, J. C. Buckey, D. A. Maloney, and C. G. Blomqvist. 1987. Cardiovascular adapta- 
tions to intense swim training in sedentary middle-aged men and women. Circulation. 75:323-330.

10. Sahn, D. J., A. DeMaria, J. Kisslo, and A. Weyman. 1978. Recommendations regarding quantitation in M-mode echocardiography: results of a survey of echocardiographic measurements. Circulation. 58:1072-1083.

11. Martin, W. H., E. F. Coyle, S. A. Bloomfield, and A. A. Ehsani. 1986. Effects of physical deconditioning after intense exercise training on left ventricular dimensions and stroke volume. J. Am. Coll. Cardiol. 7:982-989.

12. Shah, S. D., W. E. Clutter, and P. E. Cryer. 1985. External and internal standards in the single isotope derivative (radioenzymatic) assay of plasma norepinephrine and epinephrine in normal humans and persons with diabetes mellitus or chronic renal failure. J. Lab. Clin. Med. 106:624-629.

13. Gutman, I., and A. W. Wahlenfeld. 1974. L-(+)-Lactate. Determination with lactate dehydrogenase and NAD. In Methods of Enzymatic Analysis. H. U. Bergmeyer, editor. Academic Press, Inc., New York. 1464-1468.

14. Eggstein, M., and E. Kuhlman. 1974. Triglycerides and glycerol. Determination after alkaline hydrolysis. In Methods of Enzymatic Analysis. H. U. Bergmeyer, editor. Academic Press, Inc., New York. 1825-1831.

15. Evans, W. J., S. D. Phinney, and V. R. Young. 1982. Suction applied to muscle biopsy maximizes sample size. Med. Sci. Sports Exercise 14:101-102.

16. Dubowitz, V., M. H. Brooke, and H. E. Neville. 1973. Muscle Biopsy: A Modern Approach. W. B. Saunders Co., Philadelphia. 20-33.

17. Armstrong, R. B., and R. O. Phelps. 1984. Muscle fiber type composition of the rat hindlimb. Am. J. Anat. 171:259-272.

8. Martin, W. H., S. S. Murphree, and J. E. Saffitz. 1989. $\beta$-Adrenergic receptor distribution among muscle fiber types and resistance arterioles of white, red, and intermediate skeletal muscle. Circ. Res. 64:1096-1105.

19. Chi, M. M.-Y., C. S. Hintz, E. F. Coyle, W. H. Martin, J. L. Ivy, P. M. Nemeth, J. O. Holloszy, and O. H. Lowry. 1983. Effects of detraining on enzyme of energy metabolism in individual human muscle fibers. Am. J. Physiol. 244(Cell Physiol. 13):C276-C287.

20. Matthews, D. E., K. J. Motil, D. K. Rohrbaugh, J. F. Burke, V. R. Young and D. M. Bier. 1980. Measurement of leucine metabolism in man from a primed continuous infusion of $\mathrm{L}-\left[{ }^{13} \mathrm{C}\right]$ leucine. Am. J. Physiol. 238:E473-E479.

21. Matthews, D. E., K. J. Motil, D. K. Rohrbaugh, J. F. Burke, V. R. Young and D. M. Bier. 1980. Measurement of leucine metabolism in man from a primed continuous infusion of $\mathrm{L}-\left[{ }^{13} \mathrm{C}\right]$ leucine infusion in man: a method for measuring human intracellular leucine tracer enrichment. Metabolism. 31:1105-1112.

22. Schwarz, H. P., I. E. Karl, and D. M. Bier. 1980. The alpha-keto acids of branched chain amino acids: simplified derivatization for physiological samples and complete separation as quinoxalinols by packed column gas chromatography. Anal. Biochem. 108:360-366.

23. Scrimgeour, C. M., K. Smith, and M. J. Rennie. 1988. Automated measurement of ${ }^{13} \mathrm{C}$ enrichment in carbon dioxide derived from submicromole quantities of L- $\left(1-{ }^{13} \mathrm{C}\right)$ leucine. Biomed. Environ. Mass Spectrom. 15:369-374.
24. Behnke, A., and J. H. Wilmore. 1974. Evaluation and Regulation of Body Build and Composition. Prentice-Hall, Englewood Cliffs, NJ. 48-52.

25. Pollock, M. L., D. H. Schmidt, and A. S. Jackson. 1980. Measurement of cardiorespiratory fitness and body composition in the clinical setting. Compr. Ther. 6:12-27.

26. Victor, R. G., L. A. Bertocci, S. L. Pryor, and R. L. Nunally. 1988. Sympathetic nerve discharge is coupled to muscle cell $\mathrm{pH}$ during exercise in humans. $J$. Clin. Invest. 82:1301-1305.

27. Mitchell, J. H., B. J. Sproule, and C. B. Chapman. 1958. The physiological meaning of the maximal oxygen intake test. J. Clin. Invest. 37:538-547.

28. Sonnenblick, E. H., and J. E. Strobeck. 1977. Derived indexes of ventricular and myocardial function. $N$. Engl. J. Med. 296:978-982.

29. Iskandrian, A. S., L. Rose, A. H. Hakki, B. Segal, and S. A. Kane. 1983. Cardiac performance in thyrotoxicosis: analysis of 10 untreated patients. Am. J. Cardiol. 51:349-352.

30. Saltin, B., C. G. Blomqvist, J. H. Mitchell, R. L. Johnson, K. Wildenthal, and C. B. Chapman. 1968. Response to exercise after bed rest and after training. A longitudinal study of adaptive changes in oxygen transport and body composition. Circulation. 38(Suppl. VIII):1-78.

31. Coyle, E. F., W. H. Martin, S. A. Bloomfield, O. H. Lowry, and J. O. Holloszy. 1985. Effects of detraining on responses to submaximal exercise. $J$. Appl. Physiol. 59:853-859.

32. Tata, J. R., L. Ernster, O. Lindberg, E. Arrhenius, S. Pedersen, and R. Hedman. 1963. The action of thyroid hormones at the cell level. Biochem. $J$. 86:408-428.

33. Kleitke, B., G. Heier, and A. Wollenberger. 1966. Influence of thyroxine treatment on the activity of mitochondrial $\alpha$-glycerophosphate dehydrogenase in liver, heart, and skeletal muscle of several mammalian species. Biochim. Biophys. Acta. 130:270-272.

34. Winder, $W$, 1979. Time course of the $T_{3-}$ and $T_{4}$-induced increase in rat soleus muscle mitochondria. Am. J. Physiol. 236(Cell Physiol. 5):C132-C138.

35. Winder, W. W., and J. O. Holloszy. 1977. Response of mitochondria of different types of muscle to thyrotoxicosis. Am. J. Physiol. 232(Cell Physiol. 1):C180-C184

36. Nolte, J., D. Pette, B. Bachmaier, P. Kiefhaber, H. Schneider, and P. C. Scriba. 1972. Enzyme response to thyrotoxicosis and hypothyroidism in human liver and muscle: comparative aspects. Eur. J. Clin. Invest. 2:141-149.

37. Sestoft, L., and B. Saltin. 1985. Working capacity and mitochondrial enzyme activities in muscle of hyperthyroid patients before and after 3 months of treatment. Biochem. Soc. Trans. 13:733-734.

38. Gelfand, R. A., K. A. Hutchinson-Williams, A. A. Bonde, P. Castellino, and R. S. Sherwin. 1987. Catabolic effects of thyroid hormone excess: the contribution of adrenergic activity to hypermetabolism and protein breakdown. Metab olism. 36:562-569. 